\title{
Customer support phases register in enterprise management system
}

\author{
Chernenko A.F. \\ South Urals State University \\ SUSU \\ Chelyabinsk, Russia \\ 2052@bk.ru
}

\author{
Maslennikov P.P. \\ South Urals State University \\ SUSU \\ Chelyabinsk, Russia \\ pavel_chel@list.ru
}

\begin{abstract}
At present, the process of exchange of goods and services has moved to a new level: thanks to the development of technologies, the availability of the Internet and an impressive number of proposals, specialists of the marketing analysis and sales department of enterprises in various fields are looking for new ways to attract customers and improve the process of interaction between departments within their organization. Employees working with clients directly should have a clear idea of the progress of work with a particular client, and this database should be integrated into the work program of the enterprise so that with the results of running this database they could get acquainted on-line with both executives and managers, forging. This article shows a possible way to optimize the process of interaction between the department of marketing analysis and sales with internal and external environment by introducing an additional database into the existing work program. It is the register of phases of working with the client, which allows reducing the time costs for information exchange in both internal and external environment and in the external environment of the organization. The process of optimization is detailed, the phase register is presented; in fact, examples of its use are given.
\end{abstract}

Keywords - analysis, marketing, management accounting, control systems.

\section{INTRODUCTION}

Under these circumstances, a modern information field is oversaturated with the information repeating: sellers of goods and services in an attempt to attract new customers are trying to reach as many potential buyers as possible. Customers, in turn, due to the abundance of offerings on the market are becoming more discerning in market prices, and demanding a higher service level. In this regard, the sellers have to systematically inform customers about themselves: because of the abundance of offer, the potential buyer may lose contact of a particular firm, and it will be difficult in the impressive amount of carriers to find the required - so it will be easier to apply to that firm which proposed cooperation among the last.

Because of the constant offers from sellers services, buyers have become less willing to communicate with the sales: some companies receive several calls a day from various potential sellers: as a result of participating, clients become more irritable. Some representatives of sales departments choose a method of overly frequent systematic calls to customers, sending them a large number of letters to the customer. The authors of this publication believe that this scheme of work is morally obsolete; more advanced enterprises use client- oriented methodology: they study the market, identify the needs of the client, and try to find ways of possible cooperation [1].

\section{INFORMATION AVAILABILITY}

In the information technology development era, the availability of the Internet, social networks and other sources of information, the representative of marketing analysis and sales department, if they are interested in attracting and retaining the highest possible number of customers, need to change the strategy of the work in both external and internal environments: to convert broadcasting unilaterally to the dialogue between the customer and the seller [2].

The issues of interaction with customers, which were discussed a few decades ago, are not losing their relevance at present: large industrial enterprises and enterprises with smaller dimensions must listen to their customers, must be sensitive to the slightest changes in their behavior, try to fully meet the changing needs and provide service at least at the level of the client's expectations. In modern conditions, only the continuous improvement of business processes allows the company to develop [3].

The clients need to be listened and heard, to know the history of interaction with him and his plans for the future: the timely record of data on the dynamics of the development of relations with the client will help to understand the current situation, the plan for further actions will help the marketing analysis and sales department to offer the most possible ways for the client cooperation. The main thing is to remind about oneself in time. However, the manager cannot keep in his head all the information about customer: as there are many counterparties, their desires are varied, and enterprise capabilities are limited - there is a need to structure market information [4].

In order to contain market information in an easy to view and edit form, it is necessary to have a visualized algorithm of the stages of interaction with the internal and external environment of the organization, embedded into the existing computer program at the enterprise.

In relation to marketing analysis and sales department, all other units and buyers are customers [5]: other departments are the internal customers, and customers are external customers. It should be noted that often, without successful interaction with internal customers, to organize a constructive 
dialogue with external clients is problematic. So let us consider enlarging the interaction of marketing analysis and sales department of the enterprise with other departments, freight forwarding company and the clients. Therefore, it is important to create conditions for comfortable interaction between parts of the organization [6]. The information transfer rate within the company is equally important [7].

The marketing analysis and sales department sends the request to the appropriate service, and then it is further processed by a responsible employee. In the event of disputes, the parties answer the each other's questions, and then the relevant service employee responds to a request of the marketing analysis and sales department.

All information about the external and internal environment should be recorded and systematically analyzed, exclude unnecessary $[8,9,10]$. In the case with the discussion by e-mail, all correspondence of the previous dialogues should be preserved, as well as comply with a certain algorithm of the process of doing e-mails. Availability of the approved set of actions to work with e-mail, as well as the regulations of naming files and emails, will allow participants to process fast enough to find the desired file or dialogue.

Availability of statistical information for each client allows employees of marketing analysis and sales department to study the potential customer and apply appropriate marketing tools. In order to improve the competitiveness of enterprises, market-based instruments that allow the company to increase the number of counterparties are developing [11].

Currently, to obtain data about a counterparty is simple because of the abundance of open-source managers taking less time for searching the contacts than, for example, in the days of the Internet through the modem, fax machines and the absence of mobile phones. The world is changing rapidly, and now the main catch in attracting new customers is not the absence of data about the client, but an impressive number of competitors and an understanding customer's importance at the buyer market. Sales specialists at the stage of attraction of customers must understand the needs of a specific organization, because in the current environment the customer dictates the conditions, so often the service that offered a better price or better service is provided in an organization.

Periodically at some industrial enterprises, the managers for the purpose of organizing the delivery of the goods to the customer are entrust to an employee who did not face directly with the transportation process. In this regard, there are difficulties; the representative of the shipping company holds customer advice on transportation to reach an understanding. At this point, it is necessary to dwell on more detail.

Given the fact that in most cases the customer is aware of the current state of the market prices, the carrier can attract and keep their customers only with level of services quality. The problem is that the service cannot be properly evaluated until the moment when it will not be rendered, and not every customer is ready to transfer its cargo by unknown transport company. If the employee of the transport company makes a "cold call" and thereby attracts this particular participant in external economic activity, then by his actions he takes the client from his competitors. In the international cargo transportation market "free" customers are virtually nonexistent: companies engaged in foreign trade activities often already working with the transport company directly or indirectly. Also they are more or less aware of the major players in the state of this market. The so-called "Free customers" may appear as a result of leaving market by some the transport company, but often the service buyer has several contacts from the sellers, so the marketing analysis and sales department of the transport company is so important to study not only customers but also their competitors. Large industrial enterprises are well aware of the situation on the market [12], so they try to choose their business partners in a transport company that will be able to organize the delivery of the goods to the customer at the lowest cost and with the highest safety than others.

Often learning competitors occurs by studying the customers: customers usually constitute the competitive map, sending requests for freight forwarding companies to provide prices for the customer interest areas [13, 14]. In these documents, the main criterion is the cost of the provision of services [15]. However, over time, customers began to pay more attention to the service level: this is due to the fact that the exchange rate is high, and loading cost is often calculated in foreign currency, so in case of damage or loss of the goods, the customer needs to be able to compensate for their loss by the transport company.

The dilemma is that the client will not be able to really evaluate the service until he tries it on himself. Currently, for economic, political, and many other reasons, the cost of transporting the same type of transport of the same cargo along the same route can be seriously different. This is why some customers, in order to understand the service of a new potential carrier, instruct him to deliver a small shipment of cargo. At the same time, the important factor in choosing a service provider is the response time of the executor to the customer's questions, that is, the faster and more competently the client's request is processed by the carrier's manager, the higher the probability that the given client will order transportation by this transport company.

In general, it should also be noted that the compilation of long-term sales forecasts in modern conditions is quite a complex operation. The main cause is politics. As a result of the imposition of sanctions on the part of the West, some Russian entrepreneurs switched to importing products from China, similar to the European one. Of course, reorientation from Western to Eastern suppliers entails some difficulties, for example, a long search for a reliable supplier of products to China.

After selecting a supplier abroad, a participant in external economic activity needs to find a supplier of services for the delivery of goods from China. If the potential customer of the transport company previously imported goods, for example, from Germany, then in terms of delivering goods from China he may have additional questions.

If one compares the principles of delivery, for example, small shipment, then by and large the scheme of delivery by auto transport from both Europe and from China does not have 
special differences. One of the important criteria for choosing a particular service provider is the reliability of the transport operator. Often, an experienced logistician in the field of international cargo transportation at once can name at least three transport companies that can provide him with the same service with approximately the same level of quality. Another thing is if the transport company has the ability to deliver goods by its own transport both from most countries of Europe and from China, but in practice not every carrier has such opportunity. In order to offer a potential customer a service at the right time, transport company sales specialists, as they say, keep one's finger on the pulse.

To obtain from the client an order for the first transportation, at the stage of searching and attracting the client, the department of marketing analysis and sales collects as much information about the client as possible: the data are recorded in special tables, in the programs on the " $1 \mathrm{C}$ " platform: the main points are the direction and type of transportation, traffic intensity, the nature of the cargo. These data can often be found if one refers to the site of a potential client. You can get more detailed information by getting acquainted with the employee responsible for organizing the foreign economic activity at the client's enterprise.

Accumulation of information on the progress of work with the client and the formulation of certain conclusions assigned to a specific client manager will allow more effective interaction with a particular customer due to greater awareness of the counterparty. At first, entering data into the company's operating base allows this company to accumulate market information within its client departments. Secondly, with the contacts of specialists with the client from this database, the time of the latter is significantly saved: due to the timely recording of information in the database, the specialist of the seller company is quite well aware of the progress with a particular client, so the need to ask this client some questions is reduced. From the client's point of view, it is preferable to communicate with the service provider, who saves time for his clients, knows the service better than the client.

If one compares the client's attitude to the sales staff 5-10 years ago and now, at the present time the cases of rude attitude on the part of the potential customer are getting rare: due to the fact that on market there are far more transport companies than the cargo owners, carriers are forced to be more flexible. In general, a modern business is characterized by manifestations of mutual respect between members of business negotiations: each organization is in contact with contractors tends to leave a positive impression about himself. And customers understand it: they are deliberately "setting on" transport companies to reduce the cost of transportation. When comparing the client ranks, vendors based on proposals from the most obvious - the price or more other factors [16].

However, customers should understand that the price cannot be reduced to zero: some transport companies can dump to attract the customers, but this process cannot continue for a long time, since the carrier may not always operate at a loss. At the same time, the transport company can analyze its results for a certain period and take appropriate measures to increase the efficiency of its own activities. The executive discipline of individual employees, who will enter information into the working base of the enterprise, as well as visualize the process of working with the client, will help in the situation for a particular client, in order to shorten the time for the analysis of the situation.

Some of the customers are thinking that shipping cargo by road transport, for example, from Europe is identical to the delivery of modular cargo through the territory of Russia. This misunderstanding entails serious consequences for both buyers and sellers. In this regard, some transport companies are advising potential and existing customers the participation in various seminars and round tables. In general, communication with the customer is always useful for the marketing and sales department, since the customer is a kind of database, because from clients one can learn a lot of market information literally at first hand [17].

From the client's point of view, communication with the carrier is also important: transport companies monitor the changes in legislation, the political situation in those countries with which freight is being handled. Currently, transport companies need to be more open with respect to the customers, since the process of international transportation is the process of joint.

In order to offer the client what the client is looking for at the moment, employees responsible for sales need not just record information about the progress of work with an organization, but also have quick access to this information. The most convenient way to reflect a particular process is to break it down into phases and visualize the process of achieving one or another stage of working with the client.

\section{PHASE OF WORK WITH CLIENT}

During the cooperation between customer and carrier after a few traffic and getting acquainted with the specifics of the delivery of goods of a particular customer may organize the carriage fast and without questions, but until that time the executor services need to carry out a number of measures for the comprehensive study of the client.

Studying the clients is ongoing [18]: at first the transport company begins to study the customer at the time of finding secondary information about him, then the marketing manager meets with a person who makes a decision on transportation (decision maker), reveals through the organization's needs.

When a potential client offers the carrier to calculate the cost of delivery, the carrier is asking to provide more specific information about the goods and the place of loading and unloading. Client voiced the information requested; the carrier calculates the rates - the cost of services for cargo delivery on the requested route. If the client is not satisfied with the carrier's rate, the marketing and sales department tries to identify the importance of non-price criteria for the client. As soon as the parties reach a consensus, the representative of the carrier will initiate the procedure of concluding the agreement.

During the process of the contract adjustment, the marketing analysis and sales department interacts with customers and its own legal service: if necessary, they make changes to the contract or forming the disagreement protocol. 
If the parties in this case of disagreement protocol have failed to find a consensus, they form the differences agreement protocol.

The interaction process with the client is divided into several stages: from attracting the potential customer till the end of cooperation. Each of the stages, with the howling turn is divided into several phase, some of which may be reversed. The phases of work with the client (for example):

- $\quad$ phase 1: seach for general infomation about the client;

- $\quad$ phase 2:seach for the infomation about decision maker;

- phase 3: introduction of the decision maker, the presentation;

- $\quad$ phase 4: reseiving a request from a client;

- $\quad$ phase 5: query processing;

- $\quad$ phase 6: sending quotation;

- phase 7: contract conclusion;

- $\quad$ phase 8: preparation of the first transport order;

- $\quad$ phase 9: end of the first carriage;

- phase 10: processing next request;

- $\quad$ phase 11: collaboration end;

- phase 12: the analysis of the causes of shutdown.

Before the signing procedure, the parties find out whose contract form will be used. The transport company has its own form of the contract, but not every customer is willing to work on an alien form. This is due to the fact that, for example, large industrial enterprises have an impressive list of transport companies among contractors, so they want to have their own form of agreement to their legal department to spend less time on the harmonization of alien forms - much better time to have its shape as well as ban to make any changes in it. Lawyers from transport companies made their own form for the same reasons. Some carriers at the stage of concluding the contract with the customer warned in advance that making changes to the contract can only be through the formation of a disagreement protocol - the absence of disagreements notifies that the client has agreed to the transport company conditions prescribed in the standard form of contract, and if there are disagreements - the client wanted to amend the agreement in the form of the carrier, and turn to the study of these changes can be directly through disagreement protocol.

The number of customer support phases can be any, but to optimize the performance of marketing analysis and sales other departments that interact with the customer, it should be limited to their appropriate list. This "splitting" the stages of interaction with the client allows a manager to demonstrate at what specific stage the client is, what actions one needs to make to achieve a favorable development.

\section{APPLICATION USE OF PHASE DIVISION}

The prepared list of phases entered in the application software, which works with the department of marketing analysis and sales, or for clarity, every manager forms at a table in Microsoft Office Excel, which is filled by him. More clearly, the phases registry is presented below in Table 1 .
TABLE I. EXAMPLE OF PHASE REGISTER

\begin{tabular}{|l|l|l|l|l|l|}
\hline \multicolumn{1}{|c|}{ Client } & Phase 1 & Phase 2 & $\ldots . .$. & Phase n & Manager \\
\hline Firm1 & & & & & Ivanov \\
\hline Firm 2 & & & & & Petrov \\
\hline
\end{tabular}

Management may at any time refer to the table and monitor the process, making recommendations to the responsible manager for a particular client. It should be remembered about the "Law of Perspectives": the effect of innovations will manifest itself on the positive side after the accumulated amount of data for analysis [19].

As a result, senior officials, guided by the method of resources conservation, use the time and effort more efficient in dealing with a particular client [20].

For example, the transport company signed a contract with a potential client, but there were no shipping: the manager sees the data in the table. This is a signal for the manager to remind about him to the client and find out the cause of the lack of transportation. Undoubtedly, the register of phases of work with the client will be more effective when it is introduced into the existing information base of the company. This will strengthen the control of marketing information; automate the process of deducing the intermediate results of the work of staff units.

Any modern customers value their time, so they want to be served by professionals. The first contact with the client gives the overall impression to a potential customer about the title as a whole; therefore, the marketing analysis and sales department should be knowledgeable about the product / service that it offers, as one should have a rough idea of the field of activity, which one's client presents.

Filling customer support phases register allows employees of marketing analysis and sales department to analyze more fully their activities, to focus on the stage of interaction a particular client is now. It is also necessary to explain to employees that all phases of work with clients are important to the success of the client: the success of a long-term cooperation depends on the coordinated work of all participants.

If the organization uses only Microsoft Office Excel spreadsheets for marketing and there are more than one employees in the company, engaged in attracting customers, the column of names in front of each customer must be added: so for management it will be easier to analyze the performance of specific managers to compare their performance indicators.

In case of dismissal or prolonged absence of the employee in the office, one's colleagues can easily check all employee's clients, referring to the table, and then bring the client to the agreement sign phase and beyond.

The dialogue with the customer is more effective, when the representative of the transportation company promptly respond to customer requests, whether it is cost calculation and approval of the contract. Due to the fact that the marketing analysis and sales department uses an impressive part of their working time for searching new customers, a certain percentage of the time spent can be missed on the recovery of 
information that should have been, but was not completed. Due to the abundance of information and the need for multitasking, managers constantly have to prioritize.

Visualization of the process, for example, addition of the client's phase of work with the appropriate color depending on the phase, will help managers to orientate themselves in the work base of the enterprise, which client should pay more attention to the current joint work, outline plans for further development of clients.

The customer support phases register will help responsible employees to save time on recovery the information on a particular client; have an overview of progress with him. Global vision of customer service will identify inconsistencies within the enterprise, such as the delay in agreeing a contract or long-term order processing.

\section{CONCLUSIONS}

In the conditions of tough competition, enterprises in the struggle for customers use more new marketing tools. For the purpose of accounting for market information and more efficient use of the resources of its client departments, organizations are engaged in analyzing the internal and external environment, developing integrated management systems, optimizing information bases by visualizing the processes for counterparties. However, regardless of the speed of the computers of the employees of the company, the presence of a CRM-system and an impressive number of outgoing calls to potential customers from the sales department, the main resource for the competent collection and processing of market information are the employees of this enterprise. At the same time, to achieve greater results, the specialists of the marketing analysis and sales department will be able to perform the executive discipline, fix their work, summarize and plan for the future. And to analyze their actions and take measures to increase the efficiency of their work will allow compliance with the developed methodology of working with the client and visualizing the phases of interaction with it. The analysis suggests the division of the whole into parts, in this regard one needs a more detailed examination of the interaction process of the client and the seller. Separation stages of work with the client in the phase and monitoring of their condition will allow employees department of marketing analysis and sales, either in the field of international forwarding or in any other field, to control more effectively the process of interaction with the client, to attract more customers. The customer support phases register may be used in cooperation with both external and internal customers.

\section{References}

[1] F. Kotler, Osnovy marketinga, M.: Progress, 1990, 511 p.

[2] F. Kotler, Marketing. Menedzhment,SPb.: Izd-vo "Piter", 1998, 357 p.

[3] E. Deming, Vyhod iz krizisa: novaya paradigma upravlenii lyud'mi, sistemami i processami, M.: Al'pina Biznes Buks, 2007, 370 p.

[4] M.H. Meskon, M. Al'bert, F. Hedouri, Osnovy menedzhmenta, M.: Delo, 1992, $702 \mathrm{p}$

[5] M.G.Dolinskaya, I.A. Solov'ev, Marketing i konkurentosposobnost' promyshlennoy produkcii, M.: Izdatelstvo standartov, 2008, $128 \mathrm{p}$.
[6] E. A. Nezhivenko, Vzaimodeystvie konkurentosposobnosti i obrazovatel'nogo potenciala mashinostroitel'nogo predpriyatiya, CHelyab. gos. un-t. CHelyabinsk, 2003, 305 p.

[7] R.A. Fathutdinov, Strategicheskaya konkurentosposobnost': uchebnik dlya vuzov po spec. "Marketing", M.: Ekonomika, 2005, 505 p.

[8] B.V. Artamonov, Strategicheskiy menedzhment, M.: MGTUGA, 1997, $92 \mathrm{p}$.

[9] T.V. Bondarenko, Strategicheskiy menedzhment, Vladivostok: Izd-vo DVGU, 1997, 99 p.

[10] I. N. Ivanova, E. S. Orlova, Marketing kak instrument povysheniya konkurentosposobnosti, Ekonomicheskiy zhurnal, № 16, pp. 169-171, 2009.

[11] A.F. Chernenko, P.P. Maslennikov, O termine "rynochnye instrumenty" v obespechenii konkurentosposobnosti predpriyatiya, Sovremennye problemy nauki i obrazovaniya, №1, 2013.

[12] M. Porter, Mezhdunarodnaya konkurenciya, M.: Mezhdunar. Otnosheniya, 1993, 896 p.

[13] D. Preskott, S. Miller, Konkurentnaya razvedka. Uroki iz okopov, M.: Al'pina Pablisher, 2004, 336 p.

[14] A. Marshall, Principy politicheskoy ekonomii., M.: Progress, 1993, 310 $\mathrm{p}$.

[15] A.F. Chernenko, P.P. Maslennikov, Stoimost' uslug kak pokazatel' konkurentosposobnosti $\mathrm{V}$ sfere mezhdunarodnyh avtotransportnyh gruzoperevozok, Sovremennye problemy nauki i obrazovaniya, № 2, 2013.

[16] M.G. Karpunin, A.M. Kuz'min, S.V. SHaldenkov, Funkcional'nostoimostnoy analiz v inzhenernoy deyatel'nosti: uchebnoe posobie, M.: Informelektro, 1990, $77 \mathrm{p}$.

[17] D. Traut, E. Rays, Marketingovye voyny, SPb: ZAO Izdatel'stvo "Piter", 2000, 256 p.

[18] I.N. Gerchikova, Marketing i mezhdunarodnoe kommercheskoe delo, M.: Vneshtorgbdat, 1990, 49 p.

[19] D. Traut, E. Rays, 22 neprelozhnyh zakona marketinga, M.: Izd-vo "AST", 2009, 160 p.

[20] R.A. Fathutdinov, Strategicheskiy marketing, Uchebnik. M.: ZAO "Biznes-shkola "Intel-Sintez", 2000, 640 p. 